\title{
O EPISÓDIO DO CICLOPE NO CANTO IX DA ODISSEIA: UMA PARÓDIA DA CENA- TÍPICA DE HOSPITALIDADE
}

Gustavo Araújo de Freitas*

RESUMO: O episódio do Ciclope na Odisseia representa uma completa subversão dos elementos da cena-típica de hospitalidade. Mais do que isso, ele vem a ser o que Reece chamou de "uma paródia da cena-típica de hospitalidade". Logo, nosso intuito é contemplar os elementos que compõem essa cena paródica.

PALAVRAS-CHAVE: Homero; Odisseia; Ciclope; cenatípica; hospitalidade.
* garafreitas@hotmail.com

Doutorando na área de Literaturas Clássicas e Medievais do Programa de Pós-graduação em Estudos Bolsista CAPES/Reuni.

RÈSUMÉ: L'épisode du Cyclope présente une totale inversion des éléments de la scène-typique de I'hospitalité. D'ailleurs, il présente, dans sa totalité, ce que Reece a appelé une "parodie de la scènetypique d'hospitalité". En effet, notre intention c'est de contempler ces éléments qui composent cette scène parodique.

MOTS-CLÉS: Homère; Odyssée; Cyclope; scène-typique; hospitalité. 
1. Vale lembrar que o episódio é central na narrativa homérica de Polifemo o cegamento de Poseidon e os dez anos subsequentes de errância do herói da Odisseia (cf. REECE Polyphemus (Od 0. 105-564), 125). Jemny Straus 905-564), $p$. 25). Jenny Strauss Clay atenta pisódio não ape que, nesse etá ainda livre da imprecação do Ciclope e da cólera de Poseidon, como também Atena, oseidon, como também Atena, herói, está significativam do corol, es significativamente Sob esse aspecto, o episódio Sob esse aspecto, o episódio ave como seu principal feito; a rui, proeminentement coni, proemos homem da mettis (CLAY, The Wrath of Athena p. 112). Também não deixa de c. 112). Tambẽo a fale da de chamar protegido no canto $X X$, nos versos 45 a 48 (a respeito dessa mencão, 48 (a respeito dessa Wrathao, cf. ainda CLAY, The Wrath of Athena, p. 124-125).

2. Acerca disso, lembro oportunamente as palavras de Pucci (PUCCl, The I and the other in Odysseus's story of the Cyclopes, p. 117): The Cyclops is more ironic and more subtle than his gullibility in the 'Nobody' scene might suggest.

3. Lanço mão de uma expressão utilizada também por Reece (REECE, Polyphemus (Od. 9 (05-564), p. 126). Cf. ainda CLAY, The Wrath of Athena, $\mathrm{p}$. 119: a grotesque parody of the conventions regarding hospitality.
A mais odisseica das aventuras de Odisseu, o episódio do Ciclope no canto IX da Odisseia retrata a vitória da astúcia de seu protagonista sobre a selvageria de Polifemo, tendo como pano de fundo a cena-típica de hospitalidade, ou seria melhor dizer, o seu avesso, isto é, a inversão dos valores que permeiam essa cena reconhecidamente fundamental na estrutura da referida narrativa homérica como um todo.

Nesse sentido, as cenas de banquete que antecedem o episódio já preparam a audiência para reconhecer as transgressões desse selvagem, que foge, por vezes propositadamente, às regras básicas de hospitalidade; transgressões estas que condizem com sua atitude impiedosa para com os deuses e perante os hóspedes suplicantes.

Concomitantemente, porém, essa personagem monstruosa apresenta ainda uma faceta cômica, reforçada então pelo contraste advindo de seu ímpeto selvagem com traços de civilidade, por sua soberba extremada seguida de um lamento patético, por uma retórica apurada ${ }^{2}$, junto de uma ingenuidade quase pueril que não o deixa reconhecer as ciladas armadas por Odisseu.

Desse modo, todos esses elementos contribuem, em maior ou menor escala, para que o episódio do Ciclope venha a ser, no seu conjunto, o que poderíamos chamar de "uma paródia da cena-típica de hospitalidade" ${ }^{3}$

EM TESE

\begin{abstract}
BELO HORIZONTE
\end{abstract}
Nesse ponto, é oportuno destacar as considerações de Reece a respeito da particular abordagem da versão odisseica do mito do Ciclope, na qual o tema da hospitalidade permeia todo o episódio, o que, de fato, não encontramos em nenhuma outra versão das mais de duzentas lendas espalhadas pelo mundo sobre essa figura mítica. ${ }^{4}$

O autor chama a atenção para o fato de que talvez essas cenas sejam mais familiares ao público de Homero do que quaisquer outras cenas-típicas. ${ }^{5}$ Nesse sentido, ele recordaria as quatro primeiras cenas de hospitalidade - AtenaMentes em Ítaca, Telêmaco em Pilos, Telêmaco em Esparta e Odisseu na Esquéria - que imergem completamente o público em elementos convencionais, de modo que este é então preparado para reconhecer e apreciar os eventuais desvios da norma. ${ }^{6}$

E, dessa forma, Homero retoma a experiência prévia de sua audiência na Ciclopeia, utilizando-se de tais elementos, então muito bem sumariados pelo comentador, na sequência: a chegada de um estrangeiro em terra desconhecida; a apreensão do estrangeiro diante da possibilidade de o habitante ser hostil ou hospitaleiro; a recepção pelo habitante, incluindo provisão de comida e presentes de hospitalidade (xeínion); e, por fim, a questão relativa ao envio (pompéf/) do estrangeiro a seu destino. ${ }^{7}$
4. Cf. REECE, Polyphemus (Od. 9. 105-564), p. 130: In sum, Homer has transformed the inherited folktale of the blinding of a oneeyed ogre into a hospitality scene - or rather a parody of one - by introducing many typical elements of hospitality: the acquisition of gifts; the impiety of the host towards Zeus, protector of guests; the exchange of gifts, albeit deceptive ones, between guests and hosts; >>>

5. Cf. ainda REECE, Polyphemus (Od. 9. 105-564), p.124: Every hospitality scene of the Apologoi is tainted by deviations from, and perversions of, the elements of (food, song, guest-gifts, bed, etc.)

6. REECE, Polyphemus (Od. 9. 105564), p. 125. Como bem salientou Reece, as histórias narradas por Odisseu, nos livros IX a Apólogoi, lidam com um material notadamente distinto daquele do resto da Odisseia sendo derivadas de lendas e fábulas diversas, mas cujos elementos fantásticos são suprimidos em detrimento de caracteres com qualidades humanas, e sob essa perspectiva uma das mais recorrentes instituições humanas encontradas nos Apólogoi é justamente o ritual de hospitalidade (op.cit., p. 123). Para uma melhor apreciação dos elementos da cena-típica de dos elementos da cena-típica de scenes and Homeric Hospitality

7. Cf. REECE, Polyphemus (Od. 9. 105-564), p. 123.

\section{Ensino e teoria}


8. Para localizarmos o episódio do Ciclope na Odisseia, podemos considerar, num âmbito maior, o momento da chegada da frota de Odisseu na llha das Cabras, até sua partida definitiva, isto é, dos versos 105 a 566 do canto IX. Mas também podemos de forma mais precisa marcar o momento da chegada da nau de Odisseu à ilha em que habitam os Ciclopes até sua volta em segurança à lha das Cabras, do verso 181 a 542 do referido canto.

9. Como lembra Heubeck (HEUBECK, Commentary on Homer's Odyssey. Vol. 2, p. 20): os deuses fazem com que tudo cresça da terra para os ciclopes, o que năo implica qualquer crença particular neles, ou qualquer contradiçao com os veros 275-27. Acerca dessa alusăo à idade de ouro, cr. commentary of Odyssey, p. 232.

Mas vejamos com maior acuidade, passo a passo, como tais elementos se destacam no decorrer da cena, ao lado de forma indissociável da caracterização da personagem de Polifemo tal qual nos fornece o narrador do episódio, no caso, o próprio protagonista da Odisseia. ${ }^{8}$

Sendo assim, já antes do encontro com o monstro, quando da chegada da frota à "Ilha das Cabras", embora, no relato, Odisseu, junto com os companheiros, não tenha ainda se deparado com a terrível criatura, retrospectivamente, ele, enquanto narrador, nos fornece uma primeira descrição dos habitantes daquela terra e de seus costumes, criando, sem dúvida, uma atmosfera de suspense que precede tal encontro.

Logo é possível perceber a intenção de apresentar o silvícola em nítida oposição aos valores tidos como civilizados. E, de fato, embora o elemento fantástico esteja presente na própria descrição da terra, então relacionada à própria idade de ouro, tal elemento não é, sem dúvida, o mais evidenciado. ${ }^{9}$ Antes, o caráter da personagem tem como principal referência, justamente, o seu desprezo pelas instituições humanas. ${ }^{10}$ De modo que as primeiras palavras com que Odisseu apresenta os Ciclopes já os situam nessa posição antagônica: eles são arrogantes e não seguem leis (Od.IX, 106), para eles não há assembleias deliberativas, ao invés disso, vivem isolados, cada qual ditando as leis aos filhos e à mulher (Od. IX 112-115).

N. 2

AG0.-OUT. 2013
Heubeck chama atenção para o fato de que o poeta compõe a figura desses habitantes com o mais baixo nível cultural desprovida de tudo aquilo que a vida humana tem enquanto qualidade distintiva. Com efeito, seriam os Ciclopes, em um nítido contraponto com os Feácios, os quais desfrutam de todas as benesses da civilização, a incorporação do "não humano". ${ }^{1}$

Conquanto, no que diz respeito ao que Heubeck chamou de "incorporação do não humano", a distinção proposta por Pucci entre os "sobre-humanos" Feácios e os "sub-humanos" Ciclopes nos pareça mais adequada. ${ }^{12}$ Isso porque, embora a ausência de civilidade seja marcada, não podemos nos esquecer de que o Ciclope não é totalmente animalizado.

Ao contrário, os traços de humanidade estão presentes na sua própria fala, e, diga-se de passagem, com uma retórica elaborada, e ainda no seu conhecimento, mesmo que limitado, de uma tékhnē, que, embora não o permita, por exemplo, navegar até à Ilha das Cabras, ao menos lhe proporciona a utilização de utensílios rudimentares e a produção de queijos, dentre outras coisas.

E essa humanidade é, afinal, relevante enquanto parâmetro sem o qual não parece, de fato, possível qualquer julgamento de nossa parte perante as transgressões do Ciclope à norma, bem como da própria apreciação da cena paródica.
7. >> the revelation of the guest's name, lineage and homeland, albeit revealed at his departure rather than his arrival; the element rather than his arrival; the element
of the curse - replacing the typical of the curse - replacing the typical
blessing - upon the departure; blessing - upon the departure, and a appearance of an omen
upon departure. Acerca desse upon departure. Acerca desse material da tradição herdado por
Homero, cf, ainda GLENN, The Polyphemus Folktale and Homer's Kyklopeia.

10. Segundo Clay, no episódio do Ciclope o conflito entre biē (violência; força bruta) e mētis (astúcia) se expande para um âmbito de polarização da natureza e da cultura (CLAY, The Wrath of Athena, p. 126).

11. HEUBECK, Commentary on Homer's Odyssey p. 21. Acerca dessa oposição Ciclopes versus Feácios, cf. ainda CLAY, The Wrath of Athena, p. 123-132.

12. PUCCl, The I and the other in Odysseus's story of the Cyclopes, p. 124. Segundo o autor, há uma construçao estilistica com o uso de metonímias e metáforas, donde concluiríamos que os Ciclopes metaforicamente são animalizados, mas metonimicamente humanizados; enquanto os Feácios, metaforicamente humanizados e metonimicamente divinizados (op.cit., p. 118-125). Naquilo que nos interessa, diríamos que certamente o elemento humano não está ausente nem na caracterização, nem nos atos do Ciclope.

\section{Ensino e teoria}


13. DE JONG, $A$ narratological commentary of Odyssey, p. 235. Cf.

14. Od. IX, 175-176 (trad. Frederico Lourenço).

15. PUCCl, The I and the other in Odysseus's story of the Cyclopes, p. 114
Não seria um monstro como Cila ou Caríbdes, com os quais não parece possível qualquer ponto de comparação com as instituições humanas que permita a construção de uma cena paródica das mesmas.

Mas, voltando à narrativa, lembremos que Odisseu vê a fumaça subir da terra dos Ciclopes, o que, como De Jong oportunamente lembra, é tipicamente o primeiro sina de habitação humana visto por um viajante. ${ }^{13}$ Mais ainda ouvem-se deles vozes e o balido do rebanho. Logo, então, Odisseu reúne os companheiros, apresentando-lhes seu intuito de ir àquela terra para indagar: "Se são arrogantes ou selvagens, ou se prezam a justiça; /Se recebem bem os hóspedes e se são tementes aos deuses." 14

As palavras de Odisseu parecem querer retomar, de algum modo, as palavras de Alcínoo, quando este pede para que aquele lhe conte suas histórias (Od. VIII, 573- 576), ocasião em que, como lembrou Pucci, vemos já postas o que o autor chamou de anthropological coordinates. ${ }^{15}$ Logo, tais versos juntamente com a presença dos elementos supracitados, como a fumaça, as vozes, os rebanhos nos induzem a reconhecer, pelo menos a princípio, elementos humanos que Odisseu quer averiguar.

Aliado a isso, ressaltemos, como o aponta Clay, a utilização desses mesmos versos formulares em outras duas ocasiões na
Odisseia: na chegada do herói na Esquéria (VI, 120-121), e em Ítaca (XIII, 201-202). Nesses casos, a comentadora lembra que se trata de questões usuais, e que a fórmula é ainda usada por Alcínoo, quando questiona sobre as errâncias do herói (VIII, 575-576). ${ }^{16}$

Sem dúvida, não parece ser possível afirmar ainda a presença de um elemento propriamente paródico, contudo, os versos formulares, assim como a descrição de elementos humanos que despertam a curiosidade do viajante, inevitavelmente, reconduzem a audiência a um padrão de chegada do estrangeiro, já direcionando a sua atenção para o pano de fundo do episódio que começa a se desenrolar.

E é com essa expectativa que, após vermos Odisseu destacar doze de seus melhores companheiros, assistimos à partida que irá culminar no encontro com o monstro, o que o herói, ao certo, não faz sem antes se precaver de provisões para a eventual defrontação com o homem selvagem e violento, desconhecedor de leis e justiça. ${ }^{17}$

Mas a chegada, então, à terra do Ciclope, como salientou Reece, usa o modelo e a dicção típicas de uma cena de chegada, que serviria, por conseguinte, para aquela à caverna de Odisseu e seus homens, mas com um sutil desvio da norma. Chegando lá, eles não encontram o seu morador (Od., IX, 216-219), o que, por si só, já confere certa estranheza se
16. CLAY, The Wrath of Athena, $\mathrm{p}$. 115. Reinhardt lembra que esses mesmos versos são utilizados na sua chegada em Ítaca (XIII, 201202). Lá, ele se veste de mendigo e testa nobres e pessoas, servos e servas. Ele designa seu plano como alguém que está testando e pondo em prática o que Athena lhe aconselhou. Já aqui, o teste tem uma outra significação: ele leva a um irônico choque entre dois mundos, um de onde Odisseu está vindo, e outro no qual ele está entrando. Logo, ele faz o seu teste como um herói da llíada, que está acostumado a receber as mais altas honras e valiosos presentes em razão de sua posição e sua fama REINHARDT, The Adventures in the Odyssey, p. 81).

17. Cf. REINHARDT, The Adventures in the Odyssey, p. 79. Não parece que Odisseu tenha de fato uma expectativa positiva quanto ao hóspede. Parece o herói da Odisseia preparar-se para um confronto, um mal que the Sobrevenha e aos companheiros. Quanto às palavras de Odisseu em 349-350, éum blefe (um truque retórico). Não nos esqueçamos que ele planeja usar o vinho como um 'dom', ou, que seja, um 'contra-dom', de hospitalidade apenas já dentro da gruta do Ciclope.

EM TESE BELO HORIZONTE $\quad$ v. $19 \quad$ N. $2 \quad$ AG0.-0ut. $2013 \quad$ FREITAS. 0 episódio do Ciclope no canto IX da Odisseia [...] $\quad$ P. 122-136

\section{Ensino e teoria}


18. Idem.

19. Cf. REECE, Polyphemus (Od. 9. 105-564), p. 132.

20. PUCCl, The / and the other in Odysseus's story of the Cyclopes, p. 116.

21. HEUBECK, Commentary on Homer's Odyssey, p. 27: Its not easy to defend Odysseus here from the charge of folly: he still consumed by curiosity. $\mathrm{O}$ autor chama atenção ainda para os versos da Od. IX, .228 e II. V, 201.

22. CLAY, The Wrath of Athena, p. 116. A autora lança mão da expressão de Stanford para expressar os motivos de Odisseu: "inquisitiveness and acquisitiveness" (idem). Cf. aind $\mathrm{PUCCl}$, The I and the other in Odysseus's story of the Cyclopes, p. 114-115. recordarmos que esta seria a única cena de hospitalidade em Homero na qual o 'anfitrião' não se encontraria em casa. ${ }^{18}$

Mais estranho ainda, constataremos aqui uma primeira infração às regras de hospitalidade, e essa partindo justamente de Odisseu e os companheiros. Afinal, como muito bem enfatizou Reece, eles entram sem serem convidados não há um anfitrião que os convide a tomar parte em um sacrifício, como o faz Nestor em Pilos, ou oferecer-lhes as sentos e comida. ${ }^{19}$

Há, sem dúvida, uma hýbris de Odisseu, ${ }^{20}$ e não nos esqueçamos de que os companheiros tentam dissuadir o herói do seu propósito de ficar, para partirem imediatamente. ${ }^{21} \mathrm{O}$ que é em vão, pois o próprio herói confessa querer ver esse 'anfitrião' e dele receber os presentes de hospitalidade (Od. IX 229). Ora, como diria Clay, parece que o desejo de Odisseu de voltar para casa e salvar os companheiros - e que parece tão enfático no proêmio - é aqui atenuado por sua curiosidade e seu interesse pessoal. ${ }^{22}$

E, nesse ponto da história, de modo oportuno lembremos que essa motivação do herói é um elemento notadamente odisseico. Se atentarmos para o material tradicional de que dispõe o poeta da Odisseia na composição das narrativas dos Apólogoi, por exemplo, lembraríamos, como Glenn o fez, que, em poucos casos, o herói daquelas histórias tradicionais teria conhecimento do habitante da caverna e procuraria por ele, e, mesmo quando isso ocorre, em nenhum desses casos, motivado pelo interesse de presentes de hospitalidade. ${ }^{23}$

Friedrich lembra que, afinal, Odisseu está acostumado a obter bens seja pelo combate, seja pelos presentes em reconhecimento de sua honra; logo recusa o conselho anti-heróico dos companheiros. Os presentes que Odisseu espera ganhar do Ciclope devem ser vistos como sendo um análogo do géras, um presente de honra. A sua escolha de obter presentes, então, mais do que representar um anti-heróico kér dos, é parte da constante busca pela honra, philotimia. Assim, o Odisseu que embarca na aventura do Ciclope é um homem essencialmente heroico. ${ }^{24}$

E, de fato, esse seu interesse particular por presentes não é um caso isolado no conjunto da narrativa homérica. Pucci, por exemplo, chama-nos atenção para a passagem na corte dos Feácios em que Odisseu demonstra todo esse interesse (XI, 355sq). Aliás, essa passagem da Ciclopeia também ilustra o relevante comentário de Reinhardt, segundo o qual, essa seria a única aventura de Odisseu em que o herói não aparece como um sofredor, mas, ao contrário, voluntarioso e astuto, e em nenhum outro caso ele se sente tão atraído pelo perigo. ${ }^{25}$

EM TESE BELO HORIZONTE $\quad$ v. $19 \quad$ N. $2 \quad$ AGo-out. $2013 \quad$ FREITAS. 0 episódio do Ciclope no canto IX da Odisseia [...] $\quad$ P. 122-136

23. GLENN, The Polyphemus Myth: It's Origin and Interpretation, p. 151-152. Segundo o autor, na maioria das vezes as vítimas são inocentes viajantes que Nas poucas versões em que esse encontro não é exatament fortuito, dentre as motivações teríamos: o roubo do tesouro do gigante; o resgate da filha do rei; o resgate da bela donzela. o resgate da esposa (do herói): ( REECE, Polyphemus (Od a 105-564), p. 128: Of the over two hundred versions of the folktale only in Homer's version is the only in Homer's version is the hero motivated to visit the ogre is friendly to guests $(9.173-76$. cf 6-120-121: 13.201-2) and by his desire to acquire guest-guifts his desire to acquire guest-guifts
(9.228-29; 266-71).

24. FRIEDRICH, The Hybris of Odysseus, p. 22.

25. REINHARDT, The Adventures in the Odyssey, p. 79: Nothing forces him to push onward from the goat island, which offers him everything he needs, to the coast of the Cyclopes opposite [...] He is attacked by the Laistrygones because he innocently tries to find out what kind of people inhabit their land. Nothing like that happens here. He knows that the Cyclopes lives over there.

\section{Ensino e teoria}


E, por tudo isso, enfim, não deixa de ser um elemento importante na cena paródica; afinal, a expectativa por esses dons se justificaria em uma cena convencional de recepção do hóspede, mas aqui parece totalmente descabida, dado a própria expectativa que se cria em torno de quem seria esse 'anfitrião'.

Mas haverá ainda outro curioso elemento que se integra à cena paródica, e que também parte de Odisseu e seus homens: o sacrifício com queijos. De fato, Clay destacou que esse peculiar sacrifício, assim como a ágora convocada anteriormente pelo herói (Od. IX, 171), podem apenas enfatizar a ausência de tais instituições políticas e religiosas entre os Ciclopes. $^{26}$

Conquanto, não negligenciemos que quando Odisseu e seus homens começam, eles próprios, a fazer o sacrifício eles fazem a refeição e esperam pelo anfitrião, em uma evidente inversão da norma, fato para o qual também atentou Reece. ${ }^{27}$ Ou seja, não se trata apenas de enfatizar a ausência de tais instituições entre os Ciclopes; elas marcam indubitavelmente uma transgressão da parte dos supostos 'hóspedes', que além de tudo não recebem uma oferta de comida ao contrário a roubam, donde sugeriríamos que corrobora ainda com o contraste que é também característico da cena paródica.
Pois bem, na sequência, aparecerá o monstro, e seu tamanho assustador, enfatizado sem dúvida pelo herói que nos conta a história, o que também já nos dá a dimensão de seu vacilo ao deixar de dar ouvido aos companheiros antes. A criatura chega à caverna com um peso descomunal de lenha seca, o qual atira ao chão com um grande estrondo, o que já cria uma atmosfera aterradora, agravada ainda pela enorme pedra com que tapa a entrada.

Cabe mais um breve parêntese aqui para lembrar que essa lenha seria para alimentar o fogo que irá aquecer e iluminar a caverna; mas que não servirá, de fato, para cozinhar. ${ }^{28}$ Seja como for, a referência ao conhecimento do fogo confere um traço de civilidade, à exemplo do que acontece com os utensílios que são descritos mais a frente (Od. IX, 246-249).

Fechemos o parêntese e voltemos à narrativa, pois, após então realizar suas tarefas, Polifemo aviva o fogo e finalmente nota a presença dos homens. A partir daí, desenrola-se aquilo que Pucci diria como a definição da parte de Odisseu do homem social e civilizado em contraste com o selvagem. ${ }^{29}$

Nesse sentido, logo, sem titubear, o monstro já os inquire sobre a identidade (Od. IX, 252-255). E, nesse ponto, destaquemos que o hospitaleiro Nestor utiliza exatamente o mesmo conjunto de versos ao dirigir-se a Telêmaco em Pilos (Od., III, 71-74). Como salientou Reece, não se trata,
28. Cf. HEUBECK, Commentary on Homer's Odyssey, p. 27; CLAY The Wrath of Athena, p. 114.

29. PUCCl, The / and the other in Odysseus's story of the Cyclopes, p.114

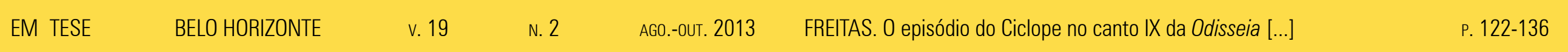

\section{Ensino e teoria}


30. Cf. ainda HEUBECK, Commentary on Homer's Odyssey, p. 28.

31. REECE, Polyphemus (Od. 9. 105564), p. 132-133.

32. PUCCl, The / and the other in Odysseus's story of the Cyclopes, p. 117

por si só, de uma interrogação hostil; no entanto, não pelo conteúdo em si, mas, sem dúvida, pela posição na sequência de elementos típicos da cena de hospitalidade, já vemos aqui nitidamente aquele contraste. ${ }^{30}$

Afinal, Polifemo pergunta pela identidade do hóspede tão logo os vê, ou seja, antes de oferecer-lhes qualquer comida, conforme seria o convencional na recepção de um hóspede, e como podemos notar não só na cena de recepção do ancião ao jovem em Pilos (3.69-70), mas também em todas as outras três cenas-típicas de hospitalidade precedentes ao episódio. ${ }^{31}$

O que constatamos então é que, se a eventual infração de Odisseu, a que nos referimos antes, pareceu, de certo modo, abrandada pelas palavras do narrador da história, aqui, ao contrário, o elemento paródico é evidenciado nessa bem marcada inversão do que seria a sequência normal dos elementos constituintes da cena-típica em questão.

Mais ainda, conforme Pucci lembra, essa repetição sugere que o Ciclope está perfeitamente familiarizado com as refinadas regras da sociedade. ${ }^{32}$ Logo, acrescentaríamos que não só a inversão na sequência esperada, mas também o fato de as mesmas palavras, antes utilizadas em um contexto de absoluto respeito à ordem social, serem agora utilizadas propositadamente pela impiedosa criatura e descumpridora das

leis e da justiça, vem a se constituir em um elemento paródico que se integra à cena.

Afinal de contas, a par de dada ambivalência no conteúdo da mensagem, o seu tom outrora pacífico contrasta nítida e ironicamente com os contornos horripilantes que serão logo a seguir evidenciados por Odisseu, ao expressar todo seu medo diante da "voz profunda" e do "ser monstruoso".

E é, pois, justamente diante desse terror personificado que, com certa prudência, o herói irá dar sua resposta: que são eles Aqueus vindos de Tróia. Ora, parece um tanto óbvio que "a fama mais excelsa debaixo do céu" (mégiston hypouránion kléos) não irá impressionar o monstro. ${ }^{33}$ Sem dúvida, um teste que nos evidencia o desdém da criatura ante os valores da épica homérica, sobretudo iliádicos. ${ }^{34}$ Como salientou Reinhardt, aqui o colapso da auto-imagem de Odisseu parece ser quase da mesma ordem de quando o herói da Iliada, armado e vestido com sua resplandecente armadura, se encontra face a face com Cila. ${ }^{35}$

Contudo, embora Odisseu não esteja ainda exatamente mentindo, ele tem o cuidado de omitir sua identidade: seu nome, sua linhagem e sua pátria, onde, conforme observou Reece, seria a ocasião esperada de o hóspede identificar-se. ${ }^{36}$ Ao invés de fazê-lo, diria o comentador, Odisseu pateticamente, na condição de suplicante e hóspede, clama pelos
33. Cf. CLAY, The Wrath of Athena, p. 117; cf. Od. IX, 264.

34. $\mathrm{Cf}$, infra.

35. REINHARDT, The Adventures in the Odyssey, p. 81.

36. Cf, REECE, Polyphemus (Od. 9. 105-564), p. 133

\section{Ensino e teoria}


37. Nesse ponto, haveria ainda a reprodução da estrutura formular dos versos 270271: "Zeus Hospitaleiro, que segue no encalço de hóspedes venerandos" (trad. Frederico Lourenço), usada nos versos do canto Vl, 206-208, onde assistimos à Nausícaa dirigir-se a suas servas na recepção de Odisseu na Esquéria. Ficaríamos, com efeito, tentados a pensar na possibilidade de um elemento que se somaria à cena paródica em que, ao contrário de uma bela jovem, o herói se depararia com a horrenda criatura. Contudo, não podemos nos esquecer de que a recepção de Nausícaa a Odisseu não se enquadra exatamente em uma cena típica de hospitalidade como aquelas aqui já mencionadas.

38. Od. IX, 272-280: Cf. REECE, Polyphemus (Od. 9. 105-564), p. 133.

39. Cf. CLAY, The Wrath of Athena, p. 117.

40. REECE, Polyphemus (Od. 9. 105564), p. 133.

41. CLAY, The Wrath of Athena, p. 118. direitos de hospitalidade em respeito a Zeus Hospitaleiro a um monstro que já deu mostras claras de sua incivilidade. ${ }^{37}$

Mais ainda, à proposição de Reece de que essa referência a Zeus como protetor dos suplicantes seria um apelo às normas da sociedade grega, ${ }^{38}$ acresceríamos que não seria normal um apelo como esse a um personagem selvagem como o Ciclope, e cuja resposta impiedosa o assinalará a seguir constituindo-se, em certa medida, também em um elemento paródico.

Resposta essa que aumentará o clima de terror ${ }^{39} \mathrm{e}$, como destacou Reece, o colocará definitivamente fora dos limites da sociedade heroica. ${ }^{40}$ Afinal, os valores iliádicos, uma vez postos à prova, não são sequer mencionados. E, se pensarmos na asserção de Clay de que Polifemo acredita unicamente na sua força como medida de superioridade, ignorando a existência daquilo que poderia superá-la, isto é, a mêtis, ${ }^{41} \mathrm{di}-$ ríamos, de nossa parte, que ele ignora também o valor odisseico por excelência.

Além disso, o selvagem expressa ainda o total desprezo por Zeus e por quaisquer regras de hospitalidade, provocando sem dúvida mais medo ainda. Com certeza, uma imagem destacadamente odisseica, para a qual encontramos raríssimos paralelos, e muito tênues, conforme lembrou Glenn além de presente em pouquíssimas versões das histórias tradicionais, na história de Homero, diferentemente delas, o desacato aos deuses torna-se um elemento central. ${ }^{42}$

Conquanto seja prudente lembrar que não devemos en tender as palavras do Ciclope simplesmente como um mero desacato. Não desconsideremos que possa ser somente mais um de seus artifícios retóricos para intimidar Odisseu e os companheiros. Seja como for, não deixa de ser um elemento central na narrativa, e, uma vez que essa é proferida por Odisseu, sem dúvida, visa reforçar o caráter monstruoso de Polifemo, e conforme podemos verificar ao final, na troca de insultos com o monstro, servirá de justificativa para seus próprios atos implacáveis. ${ }^{43}$

Assim, se pensarmos na negação de todos esses valores pelo selvagem, diríamos que, em suma, parece mesmo que, em uma primeira instância, como disse Pucci, Polifemo está zombando de Odisseu. ${ }^{44} \mathrm{E}$ é nessa contenda retórica que se inicia, que ele tenta ainda pregar uma peça no herói. Antes de dar-lhe uma mostra de sua crueldade, ele pergunta pelas naus, pondo à prova Odisseu, que, conforme era de se esperar, não vacila. Sua resposta, como lembrou Clay, seria apenas o primeiro de seus dôloi, e nós acrescentaríamos que não só a mentira, mas, a ela aliada, o próprio tom de lamento, levam ao convencimento do monstro (Od. IX, 282-286).
42. GLENN, The Polyphemus Myth: It's Origin and Interpretation, p. 157-158. Cf. ainda REECE, 128: Only in Homer's version is 128: Only in Homer's version is the gods - specifically towards Zeus, protector of guests in Homer - so explicitly articulated

and so thematically important.

43. Cf. infra.

44. PUCCl, The / and the other in Odysseus's story of the Cyclopes, p. 117.

EM TESE BELO HORIZONTE $\quad$ v. $19 \quad$ N. $2 \quad$ AG0.-0ut. $2013 \quad$ FREITAS. 0 episódio do Ciclope no canto IX da Odisseia [...] $\quad$ P. 122-136

\section{Ensino e teoria}


46. Cf. REECE, Polyphemus (Od. 9. 105-564), p.124: among the Cyclopes and Laestrygonians, the guests, rather than being offered food, actually become the food of their hosts (9.288-93; 10.115-16) [...] The guest-gift of Polyphemus - the privilege of being eaten last (9.369-70) - is a cynical parody of the normal ritual.

47. REECE, Polyphemus (Od. 9. 105564), p. 134.

48. Cf. REECE, Polyphemus (Od. 9 . 105-564), p. 135. Cf. ainda PUCCl, The I and the other in Odysseus' story of the Cyclopes, p. 117: standard gesture of strotching out standard gesture of stretching out sacrifice and banquet. ifice and banquet.

49. Tradução de Frederico Lourenço. Cf. Od. I, 149.

50. Tradução de Frederico Lourenço.

$\mathrm{O}$ que não quer dizer que ele abra mão de suas cruezas. $\mathrm{O}$ ímpio Ciclope acredita na mentira, mas não diz mais nada, apenas avança contra os companheiros, deles fazendo a sua refeição funesta (Od. IX, 287-298 ). ${ }^{45}$ O que é, sem dúvida, a máxima inversão das regras de hospitalidade: o 'anfitrião', ao invés de oferecer comida aos estrangeiros, simplesmente os come. ${ }^{46}$

Nesse ponto, destacaríamos a proposta de Reece de que Homero usa da estrutura e da dicção das cenas de um banquete normal, mas a alterando para descrever a refeição antropofágica do Ciclope. Dessa maneira, a tensão entre a dicção convencional e as inovações de Homero, isto é, os desvios da norma, acentua a absoluta perversidade da cena. ${ }^{4}$

Em consonância, a fórmula usada no verso 288 , "lançou mão" (epì kheiras íalle), retoma aquela dos versos formulares usados onze vezes por Homero na cena-típica de hospitalidade: ${ }^{48}$ "Lançaram mão às iguarias que tinham à sua frente". ${ }^{49}$ Há, sem dúvida, um efeito estilístico, diríamos um certo sarcasmo, nas palavras do poeta uma vez colocadas na boca de Odisseu; pois ele parece, de modo paródico, equiparar os companheiros às próprias iguarias de um banquete: "Mas levantou-se de repente e lançou mãos aos meus companheiros". ${ }^{50}$

Além disso, a fórmula usada no verso 291, "preparou o jantar" (hoplissato dórpon), como mais uma vez Reece chamou atenção, embora exatamente nessa forma (II, 20; IX, 344) e no seu equivalente métrico hoplissato deîpnon (IX, 311; X, 116) seja empregada na épica apenas na descrição das refeições antropofágicas do Ciclope e dos Lestrigões, muitas frases similares são atestadas em situações normais de preparação de comida. ${ }^{51}$ Logo, podemos dizer que esse recurso estilístico vem a se integrar também à cena como um de seus elementos paródicos.

Mas lembremos que, a par dessa referência a uma suposta preparação da comida, os companheiros de Odisseu podem e parecem ter sido comidos crus, o que como teria lembrado Shein, pelo modelo homérico, seria um ato de uma selvageria ainda maior do que se os tivesse cozido. ${ }^{52}$ Ademais, parece não haver necessidade dizer que a antropofagia, por si só, já se constitui em um ato de extrema barbárie, e que estejam ausentes tanto o sacrifício, quanto a partilha de comida da cena-típica de banquete.

E assim, nesse quadro de horror, é que o final da refeição será ainda marcado por um elemento paródico. Refiro-me à inversão dos versos que indicam justamente o fim de uma refeição nas cenas do banquete convencional. Nesta ocasião, lê-se: "E depois de afastado o desejo de comida e de bebida" ${ }^{53}$
51. REECE, Polyphemus (Od. 9. 105-564), p. 136. Lembremos expressões similares: II. XXIII, 55; II. VIII, 503; IX, 66); Od. IV, 429, 574; XII, 292; Od. XVI, 453; Od. $\mathrm{XIX}, 419 ;$ Od. XIV, 360.

52. SCHEIN, Odysseus and Polyphemus in the Odyssey, p. 4. $O$ autor remete-nos ainda à passagem da II.IV, 34-36.

53. Tradução nossa.

EM TESE BELO HORIZONTE $\quad$ V. $19 \quad$ N. $2 \quad$ A60.-0ut. $2013 \quad$ FREITAS. 0 episódio do Ciclope no canto IX da Odisseia [...] $\quad$ P. 122-136

\section{Ensino e teoria}


54. Od.IX, 296-297 (trad. Frederico Lourenço).

55. REECE, Polyphemus (Od. 9. 105 564), p. 136.

56. REECE, Polyphemus (Od. 9. 105564), p. 137.

57. Od. IX, $306=436$ (trad. Frederico Lourenço).

Assim, na cena do Ciclope, os versos retomam os da cena-típica, mas a glutonia da personagem é destacada ao lado de sua barbárie. Ao invés de carne de animais domésticos e sacrificáveis presente nas mesas dos banquetes odisseicos, carne humana; e, em lugar do vinho diluído em água, leite, e puro, portanto, uma dupla barbárie: "Depois que o Ciclope encheu a sua enorme barriga/ de carne humana, bebeu leite puro, sem mistura". ${ }^{54}$

Dessa forma, retomemos novamente as considerações de Reece para dizer que Homero, ao aplicar os elementos das pacíficas e civilizadas cenas de hospitalidade em uma cena de violência como essa, cria uma perversão no nível da apresentação que reflete e acentua a própria perversão da situação narrada, criando uma paródia da forma, tanto quanto do conteúdo. ${ }^{55}$

Mas as inversões da cena-típica não param por aí. Conforme complementa o comentador, após a refeição solitária, e dos próprios hóspedes, a preparação da cama, que sucederia à refeição simposial na Odisseia, incluindo nesta, canções e relatos de histórias, obviamente ausentes na Ciclopeia, é substituída pela cena do anfitrião que literalmente 'cai no sono', embriagado, enquanto os estrangeiros, em lugar de um agradável sono, restam acordados até o raiar da aurora.$^{56}$ Nesse sentido, o verso 306: "Esperámos, a chorar, que chegasse a divina aurora", ${ }^{57}$ é notadamente uma

construção paródica de um verso formular empregado em uma cena-típica de banquete: "Aí adormecemos, à espera da aurora divina". 58

Assim, o verso formular da cena-típica, que se refere ao sono tranquilo dos convivas, é utilizado no episódio do Ciclope com uma clara modificação para expressar a insônia de Odisseu e os companheiros. Estes que, na manhã seguinte, irão ainda assistir a uma segunda refeição funesta, até que Odisseu pense em um plano.

Ao certo, recordemos que o primeiro impulso do heró fora o de ferir Polifemo no peito com a sua espada, mas, caso fizesse isso, ficaria ele preso na gruta junto com os companheiros (Od. IX, 299-304). Mas a sua função na narrativa é, certamente, para que já estejamos a par de sua astúcia, à qual indissociavelmente se vincula a espera do momento oportuno, o kairós, conforme o constataremos na sequência do episódio: uma situação planeada que também levará em conta a espera da ocasião. ${ }^{59}$

Assim, ao cair da tarde Polifemo volta de suas atividades de pastoreio, e após realizar suas tarefas na gruta, e fazer sua refeição de mais dois companheiros, ${ }^{60}$ Odisseu começa a pôr em prática o seu plano.

No que concerne à cena paródica de hospitalidade, recordaríamos aqui o oferecimento de vinho da parte de Odisseu
58. Cf. Od. IX, 151; XII, 7 (trad Frederico Lourenço)
59. A princípio, a presença divina é omitida da historia. Mas e curiosa a sua menção no verso 316: "Se Atena ouvisse minha prece" (trad. Frederico Lourenço); e o fato de, logo em seguida, Odisseu avistar o tronco de oliveira, árvore reconhecidamente associada à deusa.

60. Versos formualares: Od. IX, 310$311=$ Od. IX, 343-344.

EM TESE BELO HORIZONTE $\quad$ v. $19 \quad$ N. $2 \quad$ AG0.-0ut. $2013 \quad$ FREITAS. 0 episódio do Ciclope no canto IX da Odisseia [...] $\quad$ P. 122-136

\section{Ensino e teoria}


ao Ciclope (Od.IX, 347-352). ${ }^{61}$ Ao certo, uma libação ao anfitrião atípica nas cenas de hospitalidade, mas que, não podemos nos esquecer, constitui-se indubitavelmente no truque de Odisseu para facilitar a execução de seu plano. ${ }^{62}$ Logo, essa inversão da parte do herói da Odisseia deve ser entendida não como um simples desvio da norma, embora a tenha de fato como pano de fundo. ${ }^{63}$

Já da parte do Ciclope, as transgressões são bastante claras. Para começar, ele bebe o vinho puro, sem diluir, o que, por si só, já demonstra sua barbárie. ${ }^{64}$ Além disso, não se trata de um vinho qualquer; afinal, este mesmo vinho, conforme destacou Clay, é a aquisição de uma troca de dons civilizada, mas que, agora, está sendo usado para acompanhar a refeição funesta nessa grotesca paródia de convenções de hospitalidade. ${ }^{65}$

Ademais, também a pergunta pela identidade do estrangeiro como condição para a oferta de um dom traz um elemento paródico (Od. IX, 355-356). Se recordarmos, pois, as palavras dirigidas por Alcínoo a Odisseu, nos versos 550 556 do canto VIII, e nas deste àquele, nos versos 16 a 18 do canto IX, veremos que a revelação da identidade é um pressuposto da amizade entre o hóspede e seu anfitrião; o que ironicamente, o Ciclope por um momento parece propor, em uma espécie de blefe retórico.
No entanto, Odisseu, atento à jogada de Polifemo, mais uma vez, não se dobra. Antes, o embriaga com o intuito de mais facilmente enganá-lo; o que faz, logo após outras três doses de vinho puro, na revelação da falsa identidade ao ébrio (Od. IX, 364-368). Assim, tão logo o Ciclope toma conhecimento da identidade do estrangeiro, oferece-lhe o sarcástico dom de hospitalidade. ${ }^{66}$ Pode-se dizer que as transgressões às normas que permeiam todo episódio atingem aqui o seu clímax: $:^{67}$ "Será então Ninguém o último que comerei entre os teus/ companheiros: será esse o teu presente de hospitalidade" ${ }^{6} 8$

Pucci atenta para o fato de como o Ciclope pode também jogar com as palavras e engajar-se na disputa retórica com Odisseu, afinal, Polifemo zomba do herói bem ao estilo deste último.$^{69} \mathrm{E}$, de fato, essa habilidade retórica do monstro chamou a atenção desde a Antiguidade. Demétrio, autor do tratado Sobre o estilo, afirma, por exemplo, que essa brincadeira do Ciclope é responsável por provocar um horror ainda maior dentro do episódio. ${ }^{70}$ De nossa parte, diríamos que é evidente o elemento paródico, na fala de Polifemo, dado justamente por esse contraste entre a sua habilidade retórica que o faz zombar de seu oponente, e uma incrível ingenuidade, que não o deixa perceber a cilada em que está caindo.

De modo que tão logo o Ciclope cairá, de fato, nela, pois, imediatamente após acabar de falar, embriagado ele dorme apenas ela traz o heroi e o ogro trocando dons de hospitaldidade. (REECE, Polyphemus (Od. 9. 105-564), p.128).Cf. GLENN, The Polyphemus Myth: It's Origin and Interpretation, p. 151-152.

67. Cf. REECE, Polyphemus (Od. 9. 105-564), p. 139. Clay considera 105-564), p. 139. Clay considera homérica apenas quando beta com o intuito de pervertêtla ao com o intuito de pervertê-la ao oferecer o dom de hospitalidade (CLAY, The Wrath of Athen p. 119). No entanto, não perversões vão muito além dessa perve conforme dizemos ao longo cena, conforme dize deste trabalho.

68. Od. IX, 369-370 (trad. Frederico Lourenço).

69. PUCCl, The I and the other in Odysseus's story of the Cyclopes, p. 127. Para uma abordagem mais ampla dessa relação entre o dom de hospitalidade e o nome "ninguém", cf. PODLECKI, GuestGifts and Nobodies in 'Odyssey $9^{\prime}$.

70. Cf. DEMÉTRIO, Du style, § 130.

EM TESE BELO HORIZONTE $\quad$ v. $19 \quad$ N. $2 \quad$ AG0.-0ut. $2013 \quad$ FREITAS. 0 episódio do Ciclope no canto IX da Odisseia [...] $\quad$ P. 122-136

\section{Ensino e teoria}


71. Talvez seja justamente esse contexto diverso o que nos explica o verso 318: "um deus insuflou-nos grande coragem", de fato estranho em um episódio marcado pela ausência da intervenção divina.

72. CLAY, The Wrath of Athena, $\mathrm{p}$. 118. Cf. ainda SCHEIN, Odysseus and Polyphemus in the Odyssey, náutica, cf. Od IX 385-387; acerca da metáfora do ferreiro, $c f$ Od. IX, 391-394.

73. Cf. CLAY, The Wrath of Athena, p.119-120: a mêtis de Odisseu supera enfim a bí do Ciclope.

74. Acerca desse jogo de palavras, cf. PODLECKI, Guest-Gifts and 129sq: PUCCl, The 1 and $\mathrm{p}$. 129sq; PUCCl, The I and the other in Odysseus's story of The Cyclopes, p. 126, SCHEIN, Odysseus and Polyphemus in the Odyssey, p. 79 . e é quando Odisseu coloca seu afamado plano em execução. Conforme destacado por Reece, na cena do cegamento do Ciclope, Homero abandona por um momento a dicção da cena-típica de hospitalidade, ou a paródia dela, tomando agora, por base, elementos característicos do cenário iliádico da aristéia guerreira. ${ }^{71}$

Não obstante Clay chama atenção para o fato de que a cena reforça a vitória da te/xnh, um importante componente da mêtis, segundo uma perspectiva que, lembraríamos, é predominantemente odisseica. Nesse sentido, como lembrou a comentadora, o símile que trata da perfuração do olho remetendo-se à arte da construção de navios, assim como o da queimadura provocada pela lança em brasa e que remete àquela do ferreiro, mira ao certo a ausência de tais artes entre os Ciclopes. ${ }^{72}$

E é, de fato, a vitória final da mêtis sobre a força bruta que veremos ainda quando Polifemo, já depois de cego, grita aos outros Ciclopes (Od.IX, 403-412). ${ }^{73} \mathrm{O}$ diálogo que se dá entre eles traz então o conhecido e intraduzível jogo de palavras envolvendo os termos mé tis (ninguém) e mêtis (astúcia), o que, na boca de Odisseu, soa como uma ridicularização de Polifemo. ${ }^{74}$ De tal modo que o riso triunfante do herói é também o riso do vencedor desta contenda retórica (Od. IX 413-414). E parece que, nesse ponto, temos talvez o melhor exemplo para o que comentou De Jong: que o episódio do
Ciclope apresenta o herói da Odisseia no seu melhor, mas também no seu pior: além da sua cobiça por dons, a sua arrogância na vitória. ${ }^{75}$

Mas passemos à cena seguinte; já na fuga de Odisseu e os companheiros da caverna (Od. IX, 446-461). Há ainda uma grande tensão dramática quando Polifemo aproxima-se de seu carneiro, debaixo do qual se encontra escondido Odisseu; mas, a par disso, a cena que se segue é simplesmente patética. Polifemo conversa com o seu animal preferido, o que, sem dúvida, faz com que, por um momento, nos esquecamos do perigo iminente. Heubeck diria que o poeta abala o sentimento de repúdio do leitor para com o Ciclope com a compaixão que desperta nesses versos. ${ }^{76}$

Afinal, o monstro revela-se inesperadamente mais humano e a ternura com que trata o animal dileto nada tem da violência com que se relaciona com Odisseu e seus homens. Violência que retornará ainda às suas palavras dirigidas ao carneiro, nos versos 457 a 460, num evidente contraste entre o tratamento terno conferido ao animal e aquele dado aos 'hóspedes' humanos.

Nesse ponto, lembraríamos como a figura de Polifemo é ambivalente. De Jong comenta que, ao mesmo tempo em que o monstro, com palavras e atos, zomba dos ritos de hospitalidade, ele é uma vítima digna de compaixão: o seu
75. DE JONG, A Narratological Commentary on the Odyssey, p. 231.

76. HEUBECK, Commentary on Homer's Odyssey, p. 36. Cf. ainda CLAY, The Wrath of Athena, p. 121.

EM TESE BELO HORIZONTE $\quad$ v. $19 \quad$ N. $2 \quad$ AG0.-0ut. $2013 \quad$ FREITAS. 0 episódio do Ciclope no canto IX da Odisseia [...] $\quad$ P. 122-136

\section{Ensino e teoria}


77. DE JONG, A Narratological Commentary on the Odyssey, $\mathrm{p}$ 232

78. Cf. REECE, Polyphemus (Od. 9 . 105-564), p. 140.

79. CLAY, The Wrath of Athena, p. 121.

80. SCHEIN, Odysseus and

Polyphemus in the Odyssey, p. 81.

81. Mas lembremos que a revelação não é uma simples provocação: seria um valor homérico tanto iliádico, representando a vitoria de um heró sobre o oponente, quanto um valor odisseico, uma vez que a questão da memória é um componente fundamental também dessa narrativa. cegamento é tão elaboradamente descrito - e eu diria, com requintes de crueldade -, assim como esse patético endereçamento ao carneiro. ${ }^{77}$

Pois bem, mais uma vez afastado o perigo, os homens já longe da gruta, dá-se início então à cena de partida de Odisseu da terra dos Ciclopes, que conforme mencionamos no início deste trabalho, traz a paródia da norma da cena de hospitalidade em seu desfecho. ${ }^{78}$

E, com esse cenário ao fundo, o agón retórico ainda ganha grande espaço. Odisseu clama sua força (Od. IX, 475), declarando-se a seguir (Od. IX, 478-479), conforme as palavras de Clay, o vingador da crueldade e impiedade do monstro. Como se ele próprio representasse as normas civilizadas em sua revanche contra o comportamento incivilizado. ${ }^{79} \mathrm{E}$, nesse ponto, como já o fizera Schein, lembremos como Zeus na Odisseia representa o direito moral, e tal hospitalidade é uma marca de civilização e moralidade. ${ }^{80}$

Assim, na continuação desse último agón, temos mais IX, 494-499), e, mais uma vez, o esforço sendo em vão. E na sequência, o herói revelando sua identidade (Od. IX, 501505). ${ }^{81}$ Esse ponto nos interessa diretamente, pois, como lembrou Reece, a identificação de Odisseu contém todos os elementos convencionais: nome, linhagem e pátria (cf. IX, uma vez os companheiros tentando dissuadir Odisseu ( Od

19-21). Logo, se destaca não pelo conteúdo em si, mas por sua posição na partida, e não na chegada, como seria esperado na cena-típica de hospitalidade. ${ }^{82}$

Assim, uma construção paródica na conclusão do episódio: a usual troca de bons votos na partida de um hóspede é aqui substituída pela troca de insultos. Ora, a provocação de Odisseu não tem nada do tom amigável de sua despedida dos Feácios (Od. XIII, 59-62), como observou Reece. ${ }^{83}$ Ao contrário, Odisseu, que se utiliza ainda sarcasticamente de um jogo de palavras com o termo pémpsai, sem dúvida um eco irônico da pompé/ oferecida por Polifemo em sua última cartada (Od. IX, 518), ${ }^{84}$ incita ainda mais o ódio do ferido, que, em seguida, rogará a praga que lhe trará sofrimentos sem conta para os próximos anos (Od. IX, 528-535).

$\mathrm{Na}$ fala do Ciclope - e retomemos aqui mais uma vez Reece -, a comparação com a dicção dos votos convencionais na partida de um hóspede, mostra como a imprecação de Polifemo vem a ser a negação desses votos. ${ }^{85}$ Mais ainda, como uma plena mostra de seu cinismo, suas palavras invertem aquelas de Euríalo a Odisseu no canto VIII: "E que os deuses te concedam rever a tua mulher e regressar/ à sua terra, pois há muito que sofres dores, longe da família”. ${ }^{86}$

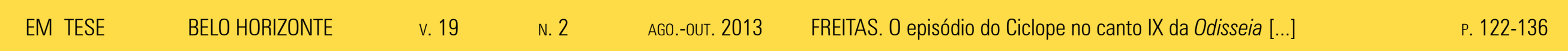

82. Idem. Assim, como na pergunta de Polifemo no início do episódio, marcada não pelo conteúdo em si mas por sua posição no que seria a sequência esperada em uma cena-típica na recepção de um estrangeiro (cf.supra)

83. REECE, Polyphemus (Od. 9. 105 564), p. 141.

84. Cf. HEUBECK, Commentary on Homer's Odyssey, p. 40.

85. Cf. GLENN, The Polyphemus Myth: It's Origin and Interpretation, p. 174-177.

86. Od. VIII, 410-411 (trad. Frederico Lourenço). Cf, ainda os votos de Helena a Telemaco em XV, 128-129; $X V, 111-112$. Quanto a isso, lembremos tambèm que só é possivel a imprecação da parte do Ciclope, após saber o nome de Odisseu.

\section{Ensino e teoria}


87. Od. IX, 532-535 (trad. Frederico Lourenço).
Reparemos, ademais, como, ainda que indiretamente, parecem ecoar de forma paródica os bons votos do jovem Feácio na boca do Ciclope:

Concede-me que nunca chegue a sua casa Ulisses, saqueador de cidades, filho de Laertes, que em Ítaca habita. Mas se for seu destino rever a família e regressar ao bem construído palácio e à terra pátria, que chegue tarde e em apuros, tendo perdido todos os companheiros,

na nau de outrem, e que em casa encontre muitas desgraças. ${ }^{87}$

E assim, no momento derradeiro do episódio, teríamos tempo ainda para esta última inversão paródica da cena de hospitalidade, e a bênção votiva convencional na partida do hóspede é sarcasticamente substituída por essa maldição que se cumprirá nos próximos dez anos de errância do herói.

\section{REFERÊNCIAS}

CLAY, Jenny Strauss. The Wrath of Athena: Gods and Men in the Odyssey. In. The wrath of Athena. New York: Rowman \& Littlefield Publishers, 1997, p. 112-132.

DÉMÉTRIOS. Du style. Trad.: Pierre Chiron. Paris: Les Belles Lettres, 1993.

DENYS D'HALICARNASSE. Opuscules rhétoriques. Trad. : Aujac et Lebel. Paris: Les Belles Lettres, 1978. Tome III.
DE JONG, Irene J. F. A Narratological Commentary on the Odyssey. Cambridge: Cambridge University Press, 2004, p. 221249

EDWARDS, Mark W. The Type-Scenes and Homeric Hospitality Transactions of the American Philological Association. The Johns Hopkins University Press, vol. 105, p. 51-72, 1975

EDWARDS, Mark W. Homer and Oral Tradition: The Type-Scene. p. 284-330.

FRIEDRICH, Rainer. The Hybris of Odysseus. Jounal of Hellenic Studies, p. 17-28, 1994

GLENN, Justin. The Polyphemus Myth: It's Origin and Interpretation. Greece \& Rome, vol. 25, n. 2, p. 141-155, 1978.

GLENN, Justin. The Polyphemus Folktale and Homer's Kyklopeia. Transactions and Proceedings of the American Philological Association. The Johns Hopkins University Press, vol. 102, p. 133-181, 1971

HEUBECK, Alfred; HOESTRA, Arie. Commentary on Homer's Odyssey. Vol. 2. Oxford: Claredon Press, 1990-1992.

HOMERI ODYSSEA. Recognovit Helmut van Thiel. Hildesheim Zürich: New York: 1991.

HOMERO, Odisseia (trad. Frederico Lourenço). Lisboa: Cotovia 2003
EM TESE
BELO HORIZONTE
v. 19
N. 2
AG0.-OUT. 2013
FREITAS. 0 episódio do Ciclope no canto IX da Odisseia [...]

\section{Ensino e teoria}


PODLECKI, A. J. Guest-gifts and Nobodies in Odyssey 9. Phoenix. Classical Association of Canada, vol. 15, n. 3, p. 125133, autumn 1961.

SAIID, Suzanne. Les crimes des prétendants, la maison

d'Ulysse et les festins de l'Odyssée. In. SAIID, DESBORDES, BOUFARTIGUE, MOREAU. Études de Littérature Ancienne. Paris: Presses de I' École Normale Supérieure, 1979, p. 9-49.

PACKARD, D. W. Sound-Patterns in Homer. Transactions of the American philological association. Baltimore, vol. CIV, p. 239260, 1974

PUCCI, Pietro. The I and the other in Odysseus's story of the Cyclopes. In: $\quad$ (org.). The song of the sirens. Essays on Homer. Lanham: Rowman \& Littlefield Publishers, 1998, p. 113-130.

REINHARDT, Karl. The Adventures in the Odyssey (transl. by Harriet I. Flower). In. SHEIN, Seth (org.) Reading the Odyssey. Princeton: Princeton University Press, 1996, p. 63-132.

REECE, Steve. Polyphemus ("Od". 9. 105-564). In:

(org.). The stranger's welcome. Oral theory and the aesthetics of the homeric hospitality scene. Ann Arbor: The Michigan University Press, 1993.

SCHEIN, Seth. Odysseus and Polyphemus in the Odyssey. Greek Roman and Byzantine Studies. Duke University, Durham, North California, vol. 11, n. 2, p. 73-83, 1970 .
VIDAL-NAQUET, Pierre. "Valeurs religieuses et mythiques de la terre et du sacrifice dans I' Odyssée". In. Le chasseur noir. Paris: François Maspero, 1977, p. 39-68.

\section{Ensino e teoria}

